\title{
Treatment of Discogenic Low Back Pain by Total Disc Arthroplasty using the Prodisc Prosthesis: Analysis of a Prospective Cohort Study with Five- Year Clinical Follow-Up
}

\author{
Gianluca Maestretti ${ }^{*},{ }^{1}$, Nikolaus Reischl ${ }^{1}$, Mathias Jacobi ${ }^{1}$, Peter Wahl ${ }^{1}$, Philippe Otten ${ }^{1}$, Titus Bihl ${ }^{2}$ \\ and Federico Balagué ${ }^{2}$
}

${ }^{I}$ Department of Orthopaedic Surgery, ${ }^{2}$ Department of Rheumatology, Cantonal Hospital Fribourg, Switzerland

\begin{abstract}
Few studies are available for the long-term outcome of disc arthroplasty using the Prodisc prostheses. We evaluated if total disc arthroplasty using the Prodisc prosthesis could be a reliable treatment for disabling low-back pain, and if long lasting improvement in quality-of-life could be achieved. We hypothesized that analysis of a prospective cohort study with a mean 5-year follow-up, clinical control, done by rheumatologists not involved in treatment would provide data that was not influenced by surgeon bias. Thirty-nine patients undergoing disc replacement between May 2002 and July 2004 were the study population. Fifty-two levels from L2 to S1, of which 28 were single-level, 9 were double-level and two were three levels, were treated. Independent clinical evaluation by uninvolved rheumatologists was done preoperatively at 1, 2 and 5 years after surgery. The Visual Analogue Score (VAS) for leg and lumbar pain intensity, Oswestry Low Back Pain Disability Index (ODI), Short Form-36 (SF-36), patient satisfaction, and the return to work rate were assessed. Analysis revealed a significant amelioration of the VAS for back and leg pain, as well as for the ODI and the SF-36. Since this is a motion preservation device study it is important to include range of motion ROM analysis at the follow-up times. These data suggest that total disc arthroplasty using the prodisc prosthesis is a good treatment option for disabling discogenic low back pain. The improvement achieved after 1 year could be conserved at 2- and 5-year follow up.
\end{abstract}

Keywords: Prodisc prosthesis, total disc arthroplasty, discogenic low back pain.

\section{INTRODUCTION}

The prevalence of chronic disabling low back pain resistant to conservative treatment is increasing, and has substantial economic and social consequences. The treatment of degenerative disc disease by total disc arthroplasty is a challenge for the spinal surgeon.

Few studies with a similar study design and no prospective cohort study, done by rheumatologists not involved directly in disc replacement treatment, have been published on the outcome of lumbar disc prosthesis [1-4].

The aim of this study was to evaluate if total disc arthroplasty using the Prodisc prosthesis can fulfil the expectations as a reliable treatment option for disabling low back pain, and whether a long lasting improvement in quality-of-live can be achieved.

\section{PATIENTS AND METHODS}

The study was approved by the internal board of the ethics committee of the cantonal hospital of Fribourg, Switzerland.

Between the 17.05.2002 and the 14.07.2004, 39 patients, 21 females (53\%, range $24-59$ years, mean age 43 years)

*Address correspondence to this author at the Department of Orthopaedic Surgery, Cantonal Hospital, 1708 Fribourg, Switzerland; Tel: +41 (0) 26 42671 11; Fax: +41 (0) 2642672 25; E-mail: maestrettig@h-fr.ch and 18 males (47\%, range $35-58$ years, mean age 46 years) underwent total disc arthroplasty. An independent evaluation of each patient took place at 1,2 and 5 years after surgery.

Fifty-eight levels from L2 to S1 were treated. Twentytwo single-level, 15 two-levels and two three-levels. Patients included:

Patients with disabling discogenic low back pain, suffering from degenerative disc disease, confirmed by standard and functional radiographs, CT, MRI and in most of the cases, by discography, were included.

Surgery was carried out by the same surgeon. All patients were eligible for total disc arthroplasty.

Only patients who were unresponsive to conservative treatment carried out for a minimum of 6 months with standard analgesic treatment, physiotherapeutic chiropractic or osteopathic therapy under regular medical supervision were included.

Postoperative care [5] included wound management pain therapy individually adapted by the anesthetist, as well as a muscular and osseous balancing under supervision of a physiotherapist.

Clinical and radiological controls took place preoperatively, 3, 6, 12, 24 and 60 months after surgery. Standing anteroposterior and lateral side radiographs, functional extension and flexion-lateral radiographs were taken.

Only clinical results were analyzed in this paper. 


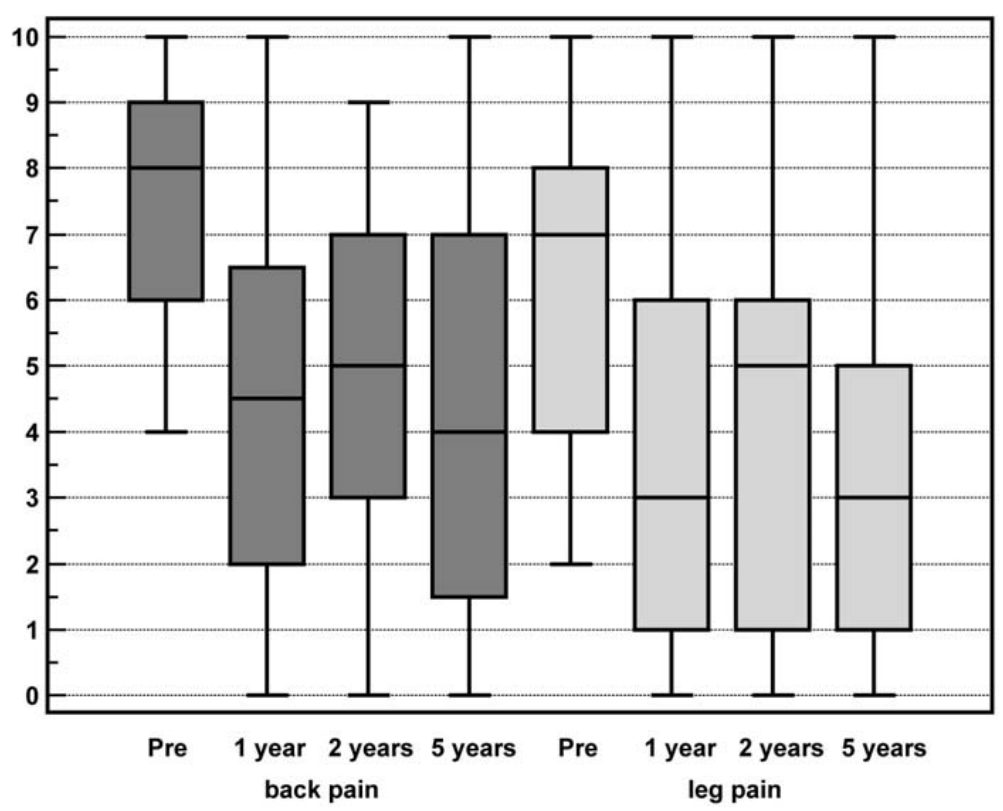

Fig. (1). VAS for back and leg pain, preoperative, at 1, 2 and 5 years.

The standard surgical approach [6], a left-side median retroperitoneal approach in accordance to the recommendation of the implantation of the Prodisc prostheses, was carried out.

Evaluation was by the Visual Analog Score (VAS); for pain in the leg and back, Oswestry Low Back Pain Disability Index (ODI), Short Form-36 (SF-36), patient satisfaction, and the return to work rate [7-9]. Statistical significance was accepted at $\mathrm{p}<0.05$.

\section{RESULTS}

Of the 39 patients (24 to 59 years) evaluated before surgery, 97\% (38) could be evaluated 1 year after surgery, $95 \%$ (37), could be evaluated 2 years after surgery, and $85 \%$ (33) 5 years after surgery. 6 patients could not be evaluated 5 years after surgery. Two patients contacted py phone were progressing well and therefore refused the radiological examination which they had to pay for themselves. Four patients living just temporary in Switzerland, moved back to their home country.

The VAS was taken to evaluate pain in the back and leg. For the back pain a decrease from 7.4 (mean) before surgery to 4.6 after 1 year, 4.6 after 2 years to $4.4(\mathrm{P}<0.0001)$ after 5 years was seen. The Visual analog score for the leg decreased from 6.2 (mean) before surgery to 3.6 after 1 year, raised to 4.2 after 2 years and decreased to $3.4(\mathrm{P}<0.0001)$ at the 5-year control (Fig. 1).

The ODI was $52.6 \%$ (mean) before surgery. We found a significant decrease of $30.7 \%$ after 1 year, at the 2 -year control a mean of $34.0 \%$ was found, and the 5-year results showed a stable significant decrease of $31 \%(\mathrm{P}<0.0001)$ (Fig. 2).

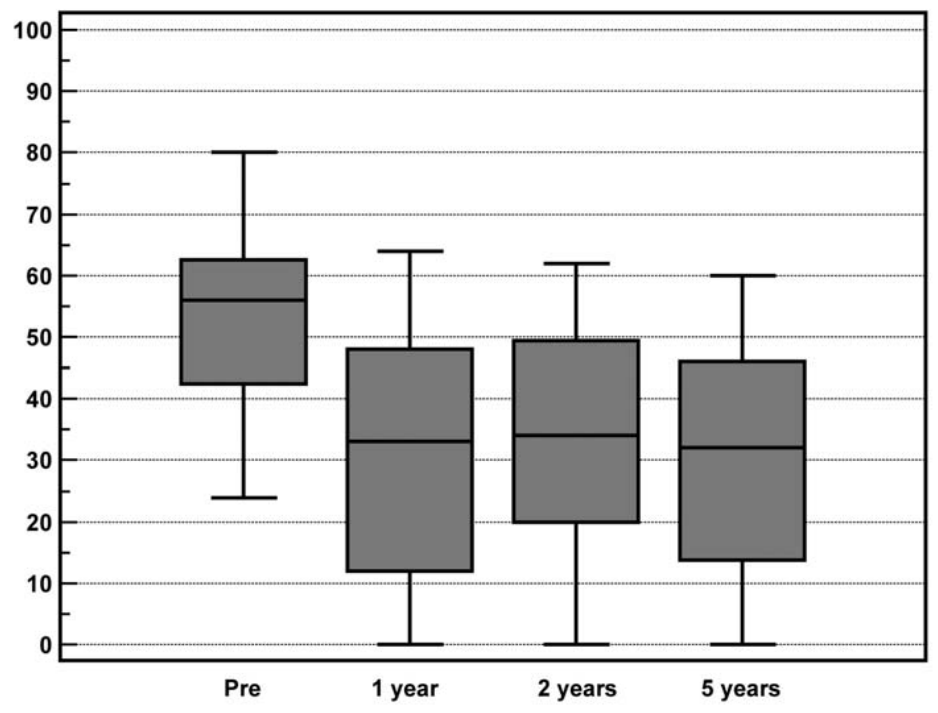

Fig. (2). ODI preoperative, at 1, 2 and 5 years. 


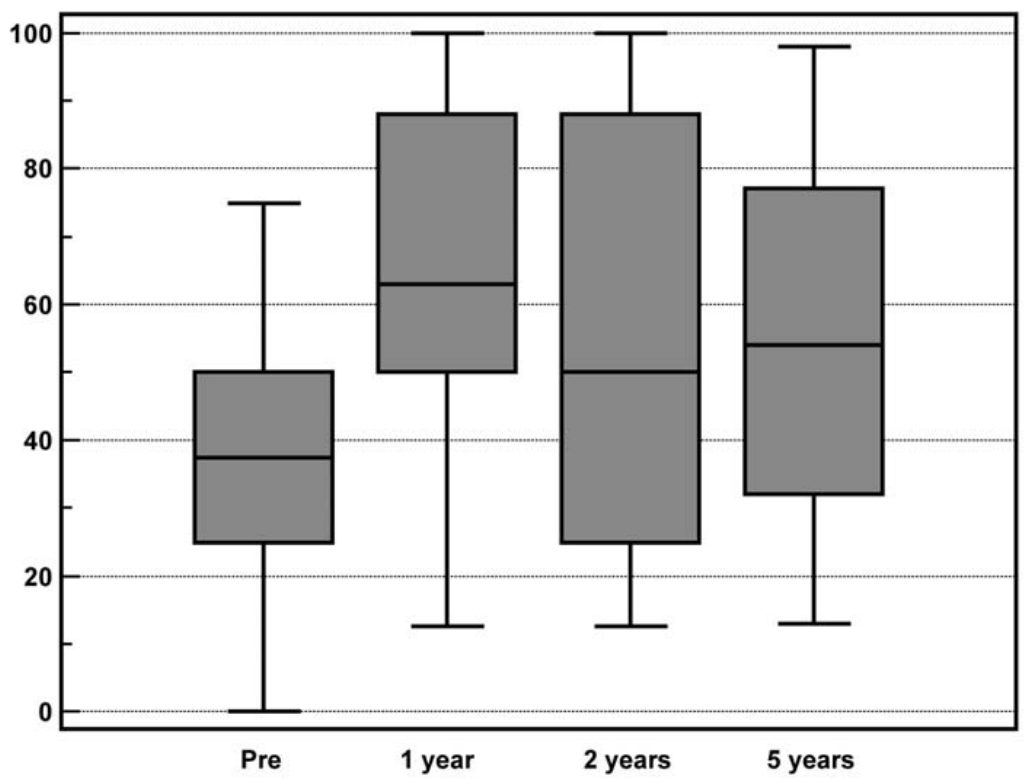

Fig. (3). SF-36 preoperative, at 1, 2 and 5 years.

Evaluation of the SF-36, showed a mean of $38.5 \%$ before surgery. An increase to $64.1 \%$ was seen at the 1 -year control. After 2 years, a decrease to $57.2 \%$ was observed. The 5 -year control showed a SF-36 of $54.7 \%$ (Fig. 3).

A statistically significant difference was not found when comparing single-level with double-level arthroplasty. Comparison of disc arthroplasty of lumbar $4 / 5$ with lumbar $5 /$ sacrall also did not show a statistically significant difference.

Radiological evaluation at the 5 years follow-up revealed that $90 \%$ of the patients had preserved motion, average flexion/extension $+/-8$ degree. Three patients $(10 \%)$ had no motion already seen at the 2 year follow up.

No signs of spontaneous fusion or heterotopic ossification according to McAfee [10].

No postoperative complication such as infection, dislocation or migration was reported. The global satisfaction score changed from $81 \%$ at the one year post operative assessment to $66 \%$ at the five year control. At what time ponit?

$92 \%$ (33 patients) answered "yes" to whether they would undergo the same surgery again, only $8 \%$ (3 patients) answered "no". There is a controversy between the global satisfaction score going down and the high percentage of Patients who answered whether they would undergo the surgery again with a "yes". This can be explained by the increase in quality of life reported with the SF36. However the achieved results could not match the high expectations which lead to a "global satisfaction score" relatively low.

At the 5-year control, $73 \%$ were still working, 39\% could resume work with the same or a higher level of activity and $33 \%$ with less working ability. Twenty-six percent of our patients could not be reintegrated in the working process; one patient was retired at the 5-year control.

Since this is a motion preservation device study, device related attributes such as motion preservation, device related complication, device migration, hetrotopic ossification, rate of adjacent level degeneration, revision surgery at the index or the adjacent levels should be reported.

\section{DISCUSSION AND CONCLUSION}

The number of surgical options to treat disabling low back pain caused by degenerative lumbar disc disease has increased over the last couple of years. Instrumented interbody spinal fusion was often the only possible treatment option, providing stability to the spine and leading to pain relief. The elimination of mobility however is thought to affect adjacent spinal segments, often causing further degeneration and chronic disabling pain $[11,12]$. Alternatives must be found to avoid this process, and to preserve or restore harmonic segmental motion. Since the late1950s, the biomechanical and physiological features of materials have been studied. Numerous prosthetic designs appeared. The Prodisc L modular prosthesis is used in our clinic, and has been implanted over 10.000 times worldwide.

Numerous studies focusing on functional and clinical outcome after Prodisc implantation have been published [14, 13-19].

Ziegler et al. [18] carried out a prospective, randomized, multicenter Food and Drug Administration Investigation device exemption study of the Prodisc-L total disc replacement versus circumferential fusion for the treatment of single-level degenerative disease. Of the 286 patients treated, Prodisc II total disc replacement in comparison with fusion showed greater satisfaction rates and a lower Oswestry score. Focusing on the Oswestry score our 1-year results confirm this tendency. At 2 years, Ziegler et al. showed a SF-36 of $79.2 \%$ in the prodisc group, compared with $70.0 \%$ in the fusion group. Our results showed a SF-36 score of $57.2 \%$ after 2 years, who remained stable at $54.7 \%$ after 5 years.

Our results are somewhat different from previously reported data $[2,3,13,20]$. "This could be due to a learning 
curve" Chung et al. reported on 36 consecutive patients after 2 years following lumbar total disc replacement using the ProDisc II prostheses [3]. Chung showed a decrease of the VAS lumbar from 7.5 preoperative to 3.0 after 2 years, and VAS leg from 4.7 preoperative to 1.2 after 2 years. Our caseload showed a VAS lumbar of 7.4 preoperative to 4.6 after 2 years and 4.4 after 5 years, and VAS leg of 6.2 preoperative to 4.2 after 2 years and 3.4 after 5 years. The ODI described by Chung et al. could as well not be confirmed by our data. His patients showed an amelioration of the ODI from 69.2 before surgery to 21.0 after 2 years. Our data showed an ODI of 52.6 before surgery, 34.0 after 2 years, and 31.1 after 5 years. Bertagnoli et al. [2] who analyzed 29 patients in his prospective study with a 2-year follow up showed a significant reduction in the VAS and ODI. VAS preoperative from 8.3 to 2.1 after 2 years, and the ODI from 65.0 to 21.6.

Siepe [20] showed different results for different levels of total disc replacement for 99 patients with a mean follow op of 25.8 months. The combined data of all groups showed a VAS preoperative of 7.0 , and of 4.0 postoperative. The ODI was $42.0 \%$ preoperative and $22.0 \%$ postoperative.

In his 2-year follow-up study after Prodisc-L total disc replacement comparing single-level versus two-level arthroplasty treatments, Hannibal [13] showed that no statistically significant difference between each category, but the VAS pain score declined from 7.2 preoperatively to 3.8 after 2 years in the single-level group, and from 7.6 to 4.8 in the two-level group. The ODI showed a decline from 63.3 preoperative to 39.0 after 2 years in the single-level group and from 63.2 to 45.7 in the two-level group. The SF-36 increased from 30.9 preoperative to 39.1 after 2 years in the single-level group, and from 30.9 to 39.0 in the two-level group. Our data did not show a statistically significant difference between the single-level and two-level group.

The difference seen in the contributions by Siepe et al. and Hannibal et al., who showed better outcome in comparison with our 2- and 5-year data, could be due to the small number of patients and a different criteria for patient selection. To compare the patient selection in our study to others is just hypothetic. An explanation for our results being less promising might be that our patients suffering from degenerative disc disease have already been in a more advanced stage compared to others. The strength of this prospective cohort study is its relatively long follow-up and the independent evaluation done by rheumatologists not involved in treatment.

The limitations of this study are the small population of patients, lack of randomization, and the absence of a control group.

The time span of 5 years for follow-up gave us a good initial data. It is not sufficient to confirm if a reduction of adjacent segmental pathologies can be expected, long-term results are needed to further evaluate this hypothesis.

Our data suggest that total disc arthroplasty is a good treatment for disabling discogenic low back pain.

We were aware that a 5-year follow-up period could give only initial information regarding longer term outcome.
Results over 10 years (including cost-effectiveness analysis) are needed to evaluate the outcome of treatment of discogenic low back pain by total disc arthroplasty.

\section{ACKNOWLEDGEMENTS}

No external funding was received. No benefits in any form were received (or will be received) from a commercial party related directly or indirectly to the subject of this contribution.

\section{CONFLICTS OF INTEREST}

The authors have no conflicts of interest related to this study.

\section{REFERENCES}

[1] Bertagnoli R, Yue JJ, Nanieva R, et al. The treatment of disabling single level lumbar discogenic lowback pain with total disc arthroplasty utilizing the ProDisc prosthesis: a prospective study with 2 year minimum follow up. Spine 2005; 30: 2230-6.

[2] Bertagnoli R, Yue JJ, Shah RV, et al. The treatment of disabling multilevel lumbar discogenic low back pain with total disc arthroplasty utilizing the ProDisc prosthesis: a prospective study with 2-year minimum follow up. Spine 2005; 30: 2192-9.

[3] Chung SS, Lee CS, Kang CS. Lumbar total disc replacement using ProDisc II: a prospective study with a 2-year minimum follow up. J Spinal Disord Tech 2006; 19(6): 411-5.

[4] Delamarter RB, Fribourg DM, Kanim LEA, et al. Prodisc artificial total lumbar disc replacement: introduction and early results from the United States. Spine 2003; 28: 167-75.

[5] Maestretti G, Otten Ph. Postoperative care after total lumbar and cervical disc replacement. Spine Art 2005; 1: 14-5.

[6] Marnay T, Tropiano P. Technique d'implantation de la prothèse Prodisc. Maitrise Orthopédique 2002; $117: 6-13$.

[7] Davidson M, Keating Jl. A comparison of five low back pain disability questionnaires: reliability and resposiveness. Phys Ther 2002; 82: 512-5.

[8] Fairbank JC, Cooper J, Davies JB, et al. The Oswestry low back pain disability questionnaire. Physiotherapy 1980; 66: 271-3.

[9] Walsh TL, Hanscom B, Lurie JD, et al. Is a condition-specific instrument for patients with low back pain/leg symptoms really necessary? The responsiveness of the Oswestry Disability Index, MODEMS, and the SF-36. Spine 2003; 28: 607-15.

[10] McAfee PC, Cunningham BW, Devine J, Williams E, Yu-Yahiro J. Classification of heterotopic ossification (HO) in artifical disk replacement. J Spinal Disord Tech 2003; 16(4): 384-9.

[11] Lee CK. Accelerated degeneration of the segment adjacent to a lumbar fusion. Spine 1988; 13: 375-7.

[12] Nachemson AL. Instrumented fusion of the lumbar spine for degenerative disorders: A critical look. In: Instrumentated fusion of the degenerative lumbar spine: State of the art, question and controversies. Philadelphia: Lippincott-Raven 1996; pp. 307-17.

[13] Hannibal M, Thomas DJ, Low J, et al. Prodisc L total disc replacement. A comparison of 1-level versus 2-level arthroplasty patients with a minimum 2-year follow up. Spine 2007; 32(21): 2322-6.

[14] Hochschuler SH, Ohnmeiss DD, Gruyer RD, et al. Artificial disc: preliminary results of a prospective study in the United States. Eur Spine J 2002; 11(Suppl 2): 106-10.

[15] Hopf C, Heeckt H, BBeske C. Disc replacement with the SB Charité endoprosthesis: experience, preliminary results and comments after 35 prospectively performed operations. Z Orthopihre Grenzgeb 2002; 140: 485-91.

[16] Tropiano P, Huang RC, Marnay $\mathrm{T}$, et al. Lumbar Total Disc Replacement. J Bone Joint Surg Am 2006; 88: 50-64.

[17] Ziegler JE. Clinical results with Prodisc: European experience and U.S. investigation device exemtion study. Spine 2003; 28: 163-6.

[18] Ziegler J, Delamarter R, Spivak JM, et al. Results of the prospective, randomized, multicenter Food and drug administration 
investigation device exemption study of the Prodisc-L total disc replacement versus circumferential fusion for the treatment of 1level degenerative disease. Spine 2007; 32: 1155-62.

[19] Tropiano P, Huang RC, Girarsi FP, et al. Lumbar disc replacement: preliminary results with ProDisc II after a minimum follow-up period of 1 year. J Spinal Disord Tech 2003; 16(4): 362-8.
[20] Siepe CJ, Mayer HM, Heinz-Leisenheimer M, et al. Total lumbar disc replacement: different results for different levels. Spine 2007; 32(7): 782-90.

Received: November 01, 2011

Revised: November 10, 2011

Accepted: November 14, 2011

(C) Maestretti et al.; Licensee Bentham Open.

This is an open access article licensed under the terms of the Creative Commons Attribution Non-Commercial License (http://creativecommons.org/licenses/by$\mathrm{nc} / 3.0 /$ ), which permits unrestricted, non-commercial use, distribution and reproduction in any medium, provided the work is properly cited. 